\title{
KONTROL KECEPATAN ROBOT HEXAPOD PEMADAM API MENGGUNAKAN METODA LOGIKA FUZZY
}

\author{
Darwison dan Rian Wahyudi \\ Laboratorium Elektronika Industri Jurusan Teknik Elektro Universitas Andalas
}

\begin{abstract}
ABSTRAK-Penelitian ini bertujuan membuat kontrol kecepatan robot hexapod pemadam api menggunakan metoda logika fuzzy. Dengan menerapkan metoda logika fuzzy akan membuat pergerakan robot lebih halus dan sebanding dengan jaraknya. Input dari metoda Logika fuzzy didapatkan dari tiga sensor ultrasonik sebagai pendeteksi jarak terhadap dinding/penghalang. Robot hexapod menggunakan servomotor dengan torgue yang cukup besar untuk melakukan pergerakan. Kecepatan robot akan lebih cepat jika tujuan pergerakan robot masih jauh dari dinding/penghalang dan sebaliknya. Mikrokontroler dengan program berbasis fuzzy logic-nya digunakan sebagai pengontrol pergerakan. Hasil percobaan menunjukkan bahwa pergerakan lebih halus berdasarkan jarak yang terbaca oleh sensor, dimana sensor mengalami kesalahan pengukuran jarak yang dipengaruhi oleh bahan dinding/penghalang. Untuk bahan dinding/pengahalang dari papan mengalami kesalahan pembacaan sebesar $0,18 \%$, buku sebesar $0,5 \%$ dan boneka sebesar $1,58 \%$.
\end{abstract}

Kata Kunci : robot hexapod, logika fuzzy, dan kontrol kecepatan

\begin{abstract}
This study aims to create a hexapod robot speed control fire extinguisher using fuzzy logic method. By applying the method of fuzzy logic will make the robot move smoother and comparable to the distance. The input of the fuzzy logic method is obtained from three ultrasonic sensors as detection distance to the wall / barrier. Hexapod robot using a servomotor with torgue large enough to perform the movement . Robot speed will be faster if the purpose of the movement of the robot is still far from the wall / barrier and vice versa . Microcontroller with fuzzy logic -based program of its use as a controller movement . The results showed that more refined movement based on the distance read by the sensor, where the sensor is experiencing an error distance measurement is influenced by the material wall / barrier . For the wall material / to obstacle of the board experienced a reading error of $0.18 \%$, amounting to $0.5 \%$ of books and dolls of $1.58 \%$.
\end{abstract}

Keywords: hexapod robot, fuzzy logic, and speed control

\section{PENDAHULUAN}

\subsection{Latar Belakang}

Agar robot dapat memberikan nilai ekonomis yang tinggi maka ia harus didisain untuk suatu tujuan tertentu (special purpose)(W. Budiharto, 2006 $)^{[1]}$. Mobile robot (robot mobil) adalah konstruksi robot yang ciri khasnya adalah mempunyai aktuator berupa roda atau kaki untuk menggerakkan keseluruhan badan robot, sehingga robot tersebut dapat melakukan perpindahan posisi dari satu titik ke titik yang lain(Darwison, 2009) ${ }^{[2,]}$ dan ((Darwison, 2011) $)^{[3,]}$. Salah satunya yaitu Robot hexapod (Robot berkaki) merupakan robot yang cukup kompleks dalam perancangan dan pembuatannya, karena perlu mempertimbangkan beberapa faktor, diantaranya keseimbangan dan kecepatan (S. Halim, 2007) ${ }^{[4]}$. Untuk melakukan pergerakan maka robot hexapod dikendalikan menggunakan mikrokontroller. Mikrokontroller Arduino merupakan pengendali mikro singleboard yang bersifat open-source, diturunkan dari Wiring platform, dirancang untuk memudahkan penggunaan elektronik dalam berbagai bidang. Perangkat kerasnya memiliki prosesor Atmel AVR dan perangkat lunaknya memiliki bahasa pemrograman yang dinamakan processing (A. Kadir, 2013 ${ }^{[5]}$. Untuk menghasilkan pergerakan robot yang lebih halus dan perubahan kecepatan sebanding dengan jarak yang mau ditempuh maka ditanamkan program sistem cerdas yang memakai Fuzzy Logic (A. Naba, 2009) ${ }^{[6]}$ pada mikrokontroller arduino. 


\subsection{Tujuan Penelitian}

Ada dua tujuan penelitian, yakni:

1. Agar dapat merancang dan membuat robot hexapod pemadam api menggunakan mikrokontroler Arduino.

2. Agar dapat membuat pergerakan robot hexapod yang lebih halus dengan menerapkan metoda fuzzy logic pada program kontrol kecepatan motornya .

\subsection{Manfaat Penelitian}

Penelitian ini adalah suatu usaha untuk dapat memberlakukan robot hexapod bergerak lebih halus dengan menerapkan program kontrol kecepatan yang ditanam di mikrokontroler Arduino memakai metoda fuzzy logic. Keberhasilan metoda ini sebagai materi penelitian diharapkan dapat memberikan hasil yang lebih efektif dalam menyelesaikan masalah, sehingga dapat berguna untuk kemajuan dunia industri dan khususnya bidang yang berhubungan dengan masalah kontrol kecepatan hexapod robot.

\subsection{Batasan Masalah}

Adapun masalah yang akan diteliti yaitu bagaimana merancang kontrol kecepatan (melibatkan sensor ultrasonik untuk deteksi jarak dan ultraviolet (UVTron) untuk deteksi api) robot hexapod dengan memakai Arduino Mega 2560 yang sudah ditanamkan program kecepatan memakai metoda fuzzy logic sehingga menghasilkan pergerakan kecepatan robot hexapod yang lebih halus.

\section{TINJAUAN PUSTAKA}

\subsection{Sistem Gerak}

Sistem gerak robot hexapod memiliki keunikan, yaitu meniru gerak pada manusia (bipedal) maupun pada binatang berkaki empat (quadrapod), berkaki enam (hexapod) seperti terlihat pada Gambar 1 dan berkaki banyak (multipod)). Semakin banyak kaki yang digunakan pada robot, diharapkan semakin seimbang robot tersebut pada saat berjalan. Robot berkaki merupakan robot yang cukup kompleks dalam perancangan dan pembuatannya, karena perlu mempertimbangkan beberapa faktor, diantaranya keseimbangan dan kecepatan(S. Halim, 2007) ${ }^{[4]}$.

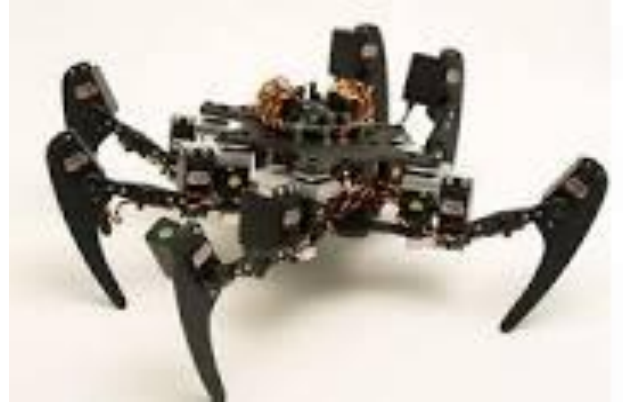

Gambar 1. Robot Hexapod ${ }^{[3]}$

\subsection{Sensor}

\subsubsection{Sensor Jarak}

Sensor PING))) ${ }^{\mathrm{TM}} \quad$ Ultrasonic Range Finder adalah sensor produksi Parallax yang hanya membutuhkan 1 pin sinyal (SIG), selain jalur Vcc (5 Volt) dan Ground seperti terlihat pada gambar 2(W. Budiharto, 2007) ${ }^{[7,[[8]}$.
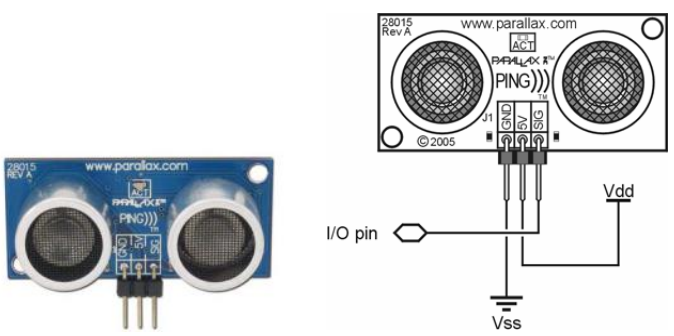

Gambar 2. Bentuk dan Konfigurasi Pin Sensor PING)) $)^{\mathrm{TM}[7]}$

Sensor PING))) ${ }^{\mathrm{TM}}$ mengukur jarak objek dengan cara memancarkan gelombang ultrasonik $(40 \mathrm{kHz})$ selama t kemudian menunggu pantulannya. Sensor PING))) ${ }^{\mathrm{TM}}$ memancarkan gelombang ultrasonik sesuai dengan input kontrol dari pin SIG (pulsa trigger dengan tout min. $2 \mu \mathrm{s}$ ). Gelombang ultrasonik ini melalui udara dengan kecepatan kurang lebih 344 meter/detik, mengenai objek dan memantul kembali ke sensor PING)) $)^{\mathrm{TM}}$. seperti gambar $3 .^{[8]}$

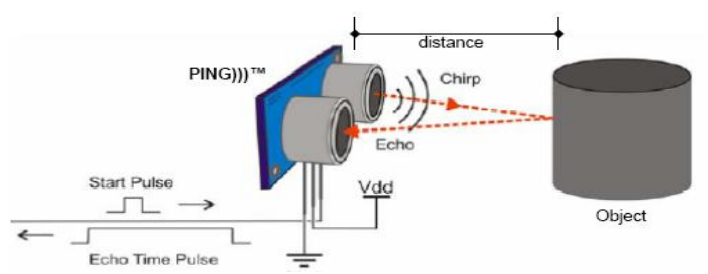

Gambar 3. Ilustrasi Cara Kerja Sensor PING)) $)^{\mathrm{TM}[8]}$ 


\subsubsection{Sensor Api}

Sensor Hamamatsu UVTron Flame Detector R2868 yang dilengkapi dengan rangkaian driver (UV Tron Driving Circuit C3704 Series) dapat mendeteksi api dari lilin atau puntung rokok yang beroperasi pada panjang spectral 185 hingga $260 \mathrm{~nm}(\mathrm{~W}$. Budiharto(2006 ${ }^{[1],[9]}$ dalam jarak 5 meter seperti pada gambar 4.

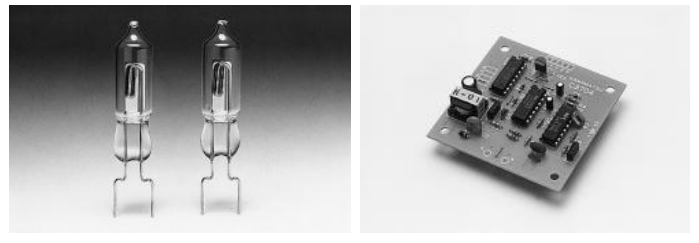

Gambar 4. Sensor Api Hamamatsu UV Tron Flame Detector $\mathrm{R} 2868$ dan rangkaian Driver $^{[9]}$

Prinsip kerja dari sensor api Hamamatsu UVTron Flame Detector yaitu pada tabung UVTron merupakan tabung yang bekerja ketika katoda diberikan sinyal ultraviolet. Ketika terjadi discharge, tabung diisi dengan elektron dan ion.

Rangkaian driver C3704 yang dioperasikan untuk sensor UV akan menghasilkan tegangan yang tinggi karena terdapat trafo step-up yang bertegangan tinggi DC.

\subsection{Mikrokontroler Arduino}

Mikrokontroler yang dipakai adalah mikrokontroler Arduino Mega 2560 yang mempunyai pengendali mikro single-board yang bersifat open-source, diturunkan dari Wiring platform, dirancang untuk memudahkan penggunaan elektronik dalam berbagai bidang. Perangkat kerasnya memiliki prosesor Atmel AVR dan perangkat lunaknya memiliki bahasa pemrograman yang dinamakan processing(A. Kadir, 2013 ${ }^{[4]}$.

Arduino adalah kit elektronik atau papan rangkaian elektronik open source yang di dalamnya terdapat komponen utama yaitu sebuah chip mikrokontroler dengan jenis AVR dari perusahaan Atmel seperti gambar 6(A. Kadir, 2013 $)^{[4]}$. Jenis Arduino yang digunakan dalam penelitian ini adalah Arduino Mega ADK yang menggunakan chip AVR ATmega 2560 yang memiliki fasilitas PWM, komunikasi serial, ADC, timer, interupt, SPI dan I2C. Sehingga
Arduino bisa digabungkan bersama modul atau alat lain dengan protokol yang berbeda-beda seperti gambar 5 .

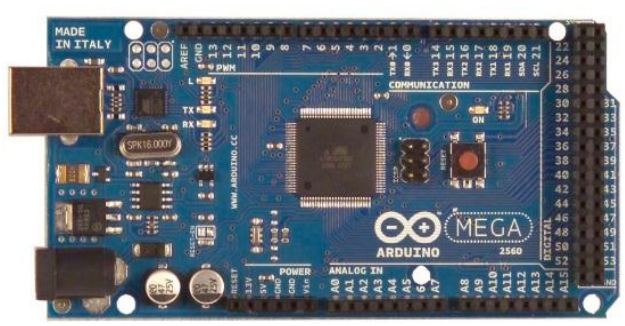

Gambar 5. Arduino Mega $2560{ }^{[4]}$

\subsection{Logika Fuzzy}

Lotfi Zadeh pada tahun 1965 mengemukakan teori tentang fuzzy set (himpunan samar) pada sebuah makalah yang berjudul "Fuzzy Sets" yaitu dapat merepresentasikan dan menangani masalah ketidakpastian yang dalam hal ini bisa berarti keraguan, ketidakpastian, kekurangan lengkapan informasi, dan kebenaran yang bersifat sebagian (A. Naba, 2009) $\left[{ }^{5]}\right.$.

\subsubsection{Fungsi-fungsi Keanggotaan}

Fungsi keanggotaan memakai fungsi segitiga untuk merepresentasikan masalah dan menghasilkan keputusan yang akurat, seperti gambar 6.

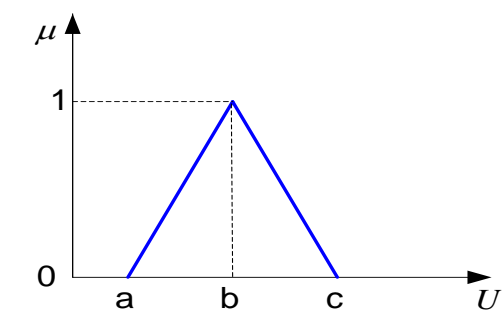

$$
\text { Triangular }(x, a, b, c)=\left\{\begin{array}{l}
0 ; x<a, x>c \\
\frac{x-a}{b-a} ; a<x<b \\
\frac{-(x-c)}{c-b} ; b<x<c
\end{array}\right.
$$

Gambar 6. Fungsi segitiga

\subsubsection{Sistem Berbasis Aturan Fuzzy}

Suatu sistem berbasis aturan fuzzy yang lengkap terdiri dari tiga komponen utama: Fuzzification, Inference dan Defuzzification(A. Naba, 2009)[ [ . 


\subsubsection{Fuzzification}

Fuzzification mengubah masukanmasukan yang nilai kebenarannya bersifat pasti (crisp input) ke dalam fuzzy input, yang berupa nilai linguistik yang semantiknya ditentukan berdasarkan fungsi keanggotaan tertentu(A. Naba, 2009)[5].

\subsubsection{Inference}

Inference melakukan penalaran menggunakan fuzzy input dan fuzzy rules yang telah ditentukan sehingga menghasilkan fuzzy output. Secara sintaks, suatu aturan fuzzy dituliskan sebagai:

\section{IF antecendent THEN consequent.}

Terdapat dua model aturan fuzzy dan pada penelitian ini memakai model Mamdani.

\section{- $\quad$ Model Mamdani}

Pada model ini, aturan fuzzy didefinisikan sebagai:

IF $x_{1}$ is $A_{1}$ AND ... AND $x_{n}$ is $A_{n}$ THEN $y$ is $B$ dimana $A_{1}, \ldots, A_{n}$, dan $B$ adalah nilai-nilai linguistik dan " $\mathrm{x}_{1}$ is $\mathrm{A}_{1}$ " menyatakan bahwa nilai variabel $\mathrm{x}_{1}$ adalah anggota fuzzy set $\mathrm{A}_{1}$.

\subsubsection{Defuzzification}

Defuzzification mengubah fuzzy output menjadi crisp value berdasarkan fungsi keanggotaan yang telah ditentukan. Terdapat berbagai metode defuzzification yang telah berhasil diaplikasikan untuk berbagai macam masalah, diantaranya(A. Naba, 2009) [ ${ }^{5}$ :

\section{- Weigthed Average}

Metode ini mengambil nilai rata-rata dengan mengunakan pembobotan berupa derajat keanggotaan. Sehingga $y^{*}$ didefinisikan sebagai:

$$
y^{*}=\sum \frac{\mu(y) y}{\mu(y)}
$$

Dimana y adalah nilai crisp dan $\mu(\mathrm{y})$ adalah derajat keanggotaan dari nilai crispy.

\section{METODOLOGI PENELITIAN}

\subsection{Perancangan Sistem}

Pada perancangan sistem ini akan dijelaskan secara garis besar bagaimana robot akan berkerja terhadap perubahan jarak, pembacaan titik api dan pergerakan kaki-kaki robot. Perangkat ini meliputi perancangan perangkat keras dan perangkat lunak seperti gambar 7.

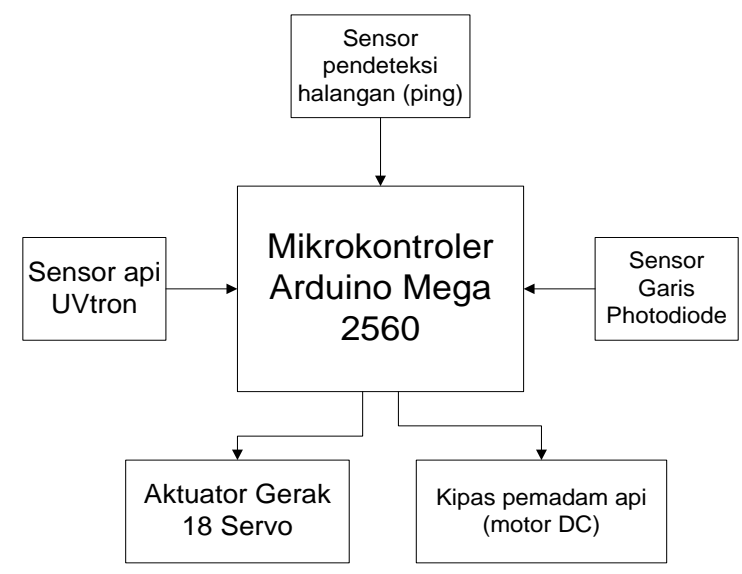

Gambar 7. Diagram blok Robot Hexapod

Dari gambar 7, mengambarkan robot akan dapat mengetahui jarak terhadap penghalang. Dari besarnya jarak yang didapat, robot akan menyesuaikan arah pergerakan robot. UVtron akan mengecek ada tidaknya titik api dan sensor garis sebagai pembacaan titik keberadaan api.

\subsection{Perancangan Perangkat Keras}

Perancangan perangkat keras berupa perancangan mekanik yang terdiri dari komponen utama penyusun robot yang terdiri dari sebuah mikrokontroler sebagai otak dari robot, sensor garis, sensor jarak dan sensor api serta motor sebagai penggerak dari robot seperti gambar 8. Gambar 8 (a) robot hexapod dan (b) simulasinya menggunakan program Proteus. Motor servo sebagai penggerak kaki robot dan motor DC penggerak kipas pemadam api(E. Pitowarno, 2006) $)^{[8]}$. 


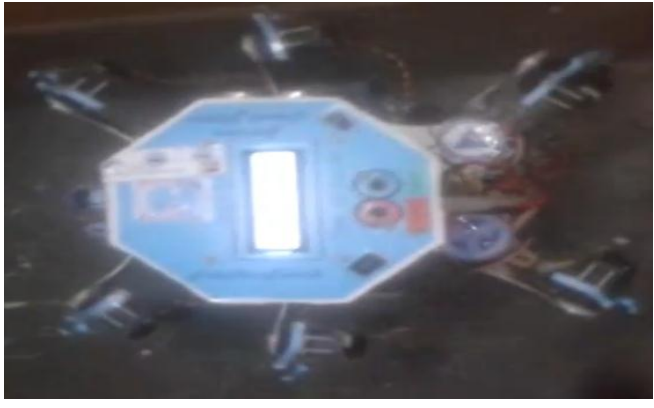

(a)

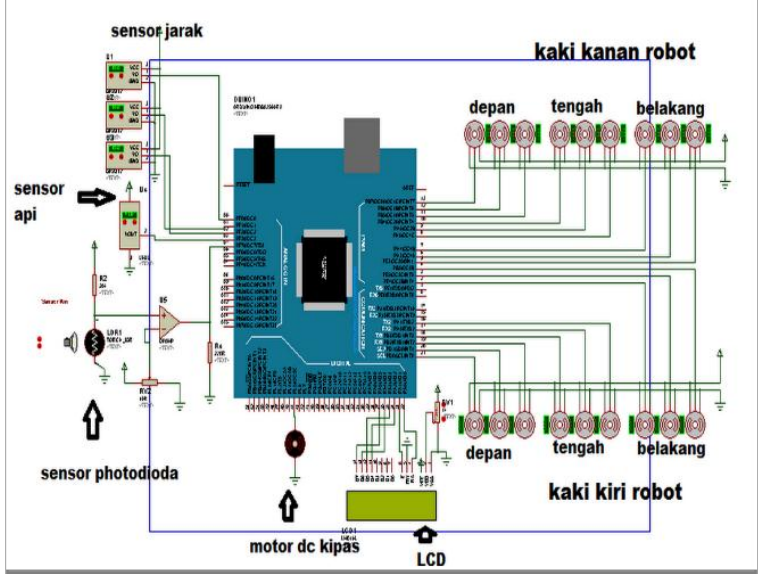

(b)

Gambar 8. (a) robot hexapod dan (b) simulasinya

\subsection{Perancangan Perangkat Lunak}

Perancangan program yang digunakan dalam sistem robot seperti pada gambar 9 .

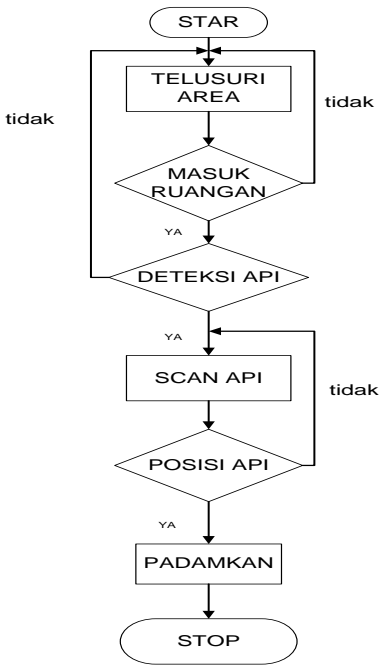

Gambar 9. Diagram alir kontrol robot hexapod

\subsection{Perancangan Program motor Servo}

Pada IDE menyediakan library yang sangat membantu dalam melakukan peranan perangkat lunak pada robot hexapod.

\section{\#include <servo.h>}

Servo.h merupakan library untuk servo kontroler sehingga 18 buah motor servo dapat dikontrol melalui mikrokontroler. Motor servo berfungsi sebagai pergerakan dari kaki-kaki robot yang dapat diatur akselerasi pergerakan masingmasing kaki.

\subsection{Perancangan Program Sensor Ultrasonik}

Sensor ultrasonik berperan penting dalam sistem navigasi robot yaitu sebagai subsistem yang akan menghitung jarak robot dengan dinding. Miktrokontroler mengirimkan pulsa(triger pulsa) minimal sebesar 2Error! Reference source not found.

\subsection{Perancangan Kontrol Logika Fuzzy}

Logika Fuzzy merupakan logika kendali cerdas yang digunakan untuk mengendalikan arah pergerakan langkah kaki-kaki robot. Input data dari logika fuzzy berasal dari pembacaan tiga buah sensor jarak dan sebagai keluarannya adalah arah pergerakan robot memakai 3 servo per kaki seperti skema kendali fuzzy pada gambar 10.

Adapun diagram alir proses logika fuzzy sebagai pengendali dari robot hexapod seperti pada gambar 11.

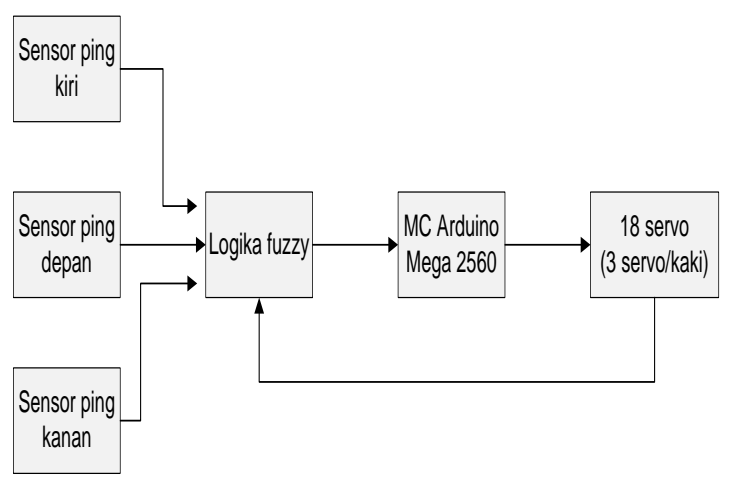

Gambar 10. Skema kendali fuzzy 


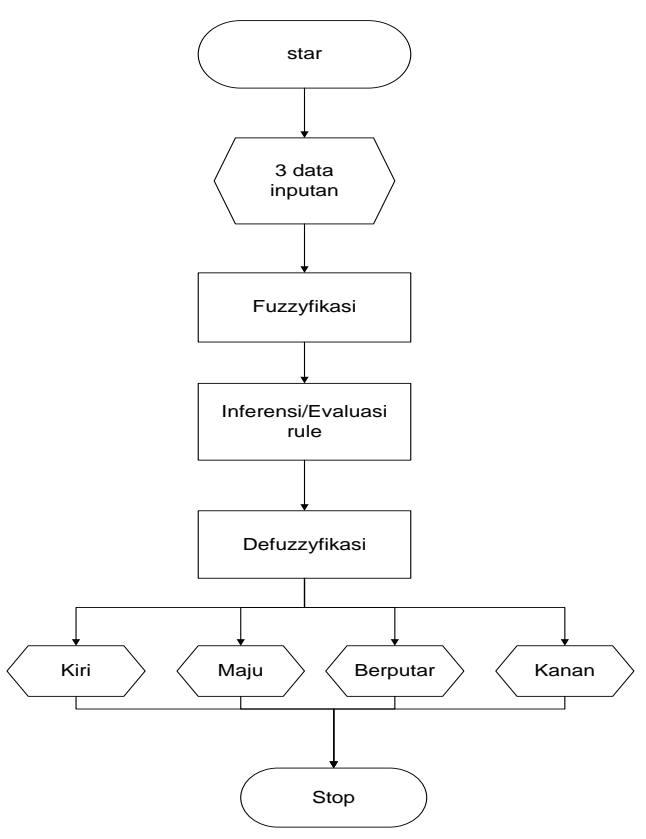

Gambar 11. Diagram Alir Proses Logika Fuzzy

\section{HASIL DAN PEMBAHASAN}

\subsection{Hasil Pengujian Sensor Ultrasonik}

Pada gambar 12 sampai gambar 15 terlihat grafik pengukuran dari sensor ping tidak stabil atau berubah-ubah tiap detiknya sesuai bahan penghalang dan perubahan jarak robot. Hal ini juga dikarenakan sifat dari sensor ping itu sendiri, dimana Crips mengirimkan pulse berubah-ubah setiap saat, dengan pulse minimum $115 \mu$ s dan maksimum $18.5 \mathrm{~ms}$.

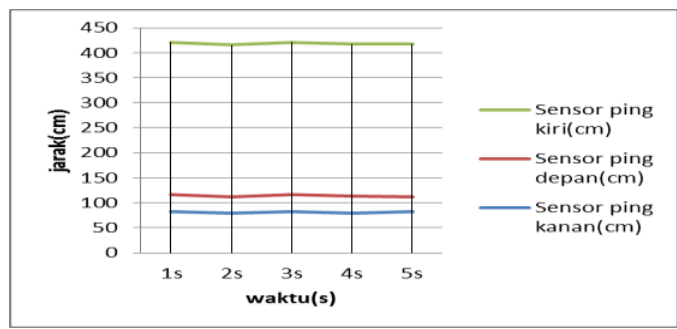

Gambar 12. sensor ping tanpa halangan

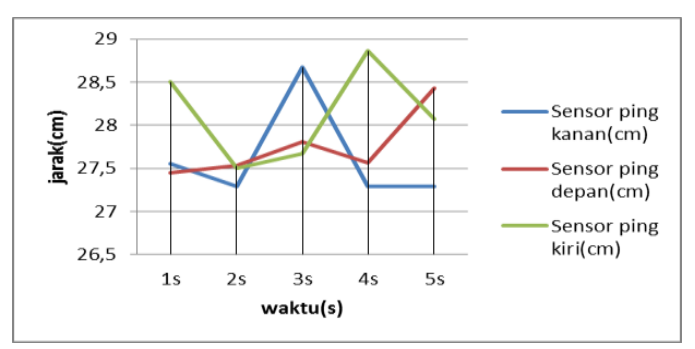

Gambar 13. sensor ping halangan papan

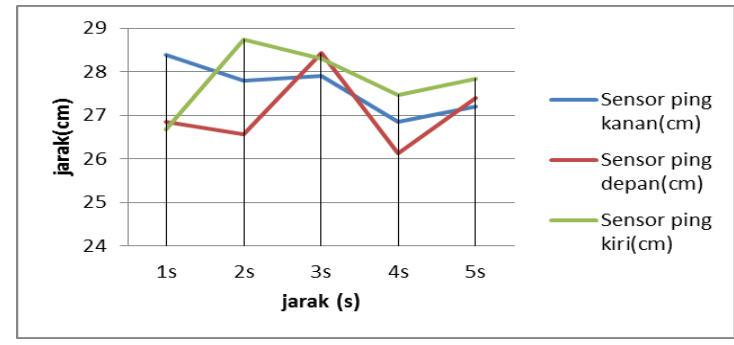

Gambar 14. sensor ping dengan halangan buku

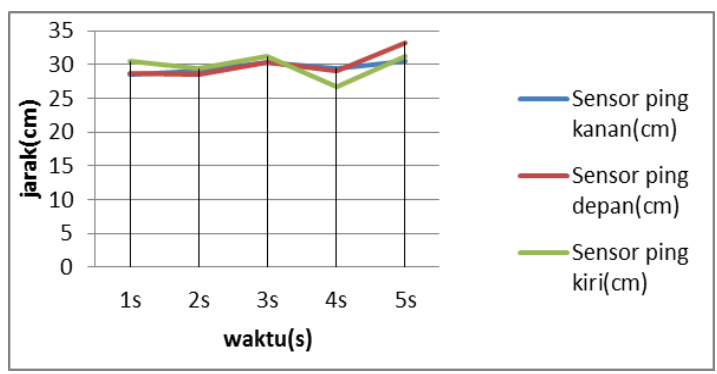

Gambar 15. sensor ping dengan halangan boneka

Sesuai dengan teori bahwa benda padat lebih baik memberikan pemantulan dari pada benda yang lembut. Berdasarkan gambar diatas didapatkan \% nilai error pada masing-masing halangan didapatkan bahwa benda padat (papan) adalah $0.18 \%$, semi padat (buku) $0.50 \%$ dan benda lembut (boneka) $1.78 \%$.

\subsection{Hasil Pengujian UVtron}

Objek pembacaan sensor UVTron mengunakan sumber api berupa lilin. Pendeteksian dilakukan tanpa adanya halangan dan pengujian dilakukan dengan berbagai jarak dengan keluaran ditampilkan pada LCD. Pulsa high (pulsa "1") yang dihasilkan oleh kaki pin 1 dari rangkaian driver sensor UVTron jika terdeteksi ada api maka pada LCD akan menampilkan api terdeteksi atau tidak. Pada pengujian didapatkan jarak terjauh yang dapat dideteksi oleh UVtron adalah 5 meter.

\subsection{Hasil Pengujian Pergerakan Robot}

Dari gambar 16 dan gambar 17 terlihat kecepatan robot meningkat saat jarak tempuh masih jauh. 


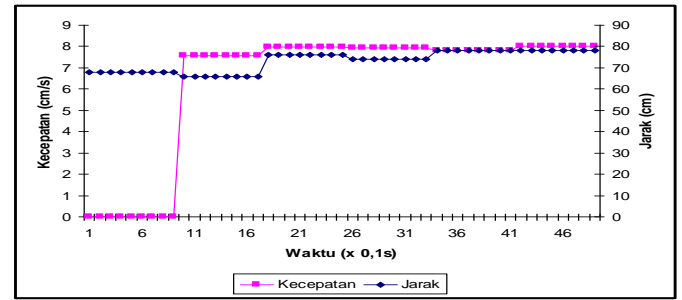

Gambar 16. Jarak penghalang 0.8 meter

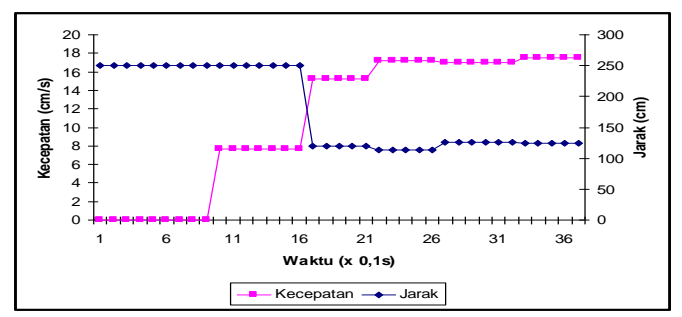

Gambar 17. Jarak penghalang 1,2 meter

Perubahan kecepatan robot berdasarkan pada perhitungan jarak dari sensor ultrasonik serta perhitungan kecepatan riil pada pergerakan kaki-kaki robot. Dengan menggunakan logika fuzzy dapat dilakukan perubahan kecepatan yang lebih halus dengan variasi dari besar sudut motor servo pada masing-masing bagian kaki robot.

\subsection{Hasil Pengujian Robot Mencari dan Memadamkan Api}

Pengujian sistem keseluruhan dari robot yang terdiri dari 3 sensor ping, sensor photo dioda dan sensor UVtron. Masing-masing sensor memegang peranan penting dalam menstimulasi pergerakan dan perilaku robot. Analisis ini dilakukan dengan meletakan titik api(lilin) pada ruangan tertentu seperti gambar 18 dan robot diaktifkan pada ruangan yang berbeda. Robot berjalan menelusuri lintasan tersebut menuju titik api(lilin) dan memadamkan api.

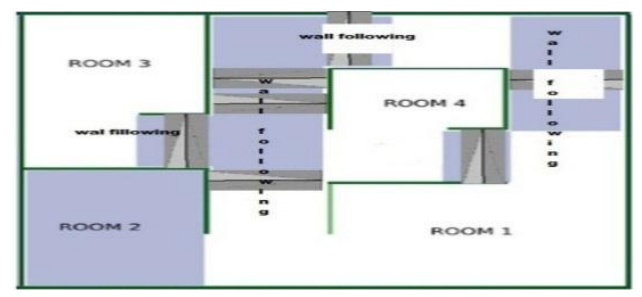

Gambar 18. Track Pengujian Robot Mencari Titik Api

\section{KESIMPULAN}

Dari hasil pengujian alat dan analisa dapat diambil kesimpulan:

1. Benda padat akan memantulkan sinyal ultrasonik yang lebih baik dibandingkan dengan benda yang kurang/tidak padat berdasarkan hasil error-nya pada papan(keras) sebesar $0,18 \%$, buku(agak keras) $0,50 \%$,dan Boneka(lunak) 1,58\%.

2. Sensor UVTron dapat membaca titik api dengan jarak terjauh 5 meter.

3. Dengan menggunakan logika fuzzy dapat dilakukan perubahan kecepatan yang lebih halus dengan variasi dari besar sudut motor servo pada masing-masing bagian kaki robot.

\section{DAFTAR PUSTAKA}

[1] Budiharto, Widodo, Belajar Sendiri Membuat Robot Cerdas, PT Elex Media Komputindo, Jakarta(2006).

[2] Darwison dan Ade Ermadi, Perancangan dan Implementasi Robot Mobil Pendeteksi dan Pemadam Api Menggunakan Sensor Ultrasonik dan Sensor Ultraviolet Berbasis Mikrokontroler Renesas R8C/13. Teknika, Unand-Padang(2009).

[3] Darwison, M. Ilhamdi Rusydi dan Imil Hamda Imran, Perancangan dan Pembuatan sistem Kontrol Kecepatan Servomotor Continous Parallax dengan PID. Teknika No.35 Vol.1 thn.XVIII, Universitas Andalas Padang (2011).

[4] Halim, Sandy, Merancang Mobile Robot Pembawa Objek Menggunakan OOPic-R, PT Elex Media Komputindo, Jakarta(2007).

[5] Kadir, Abdul, Panduan Praktis mempelajari Aplikasi Mikrokontroler dan Pemrogramannya menggunakan Arduino, , Penerbit Andi(2013).

[6] Naba, Agus, Belajar Cepat Fuzzy Logic menggunakan Matlab, Penerbit Andi(2009).

[7] Budiharto, Widodo dan Gamayel Rizal, 12 proyek mikrokontroler untuk pemula, Elex Media Komputindo, Jakarta(2007).

[8] Datasheet Devantech SRF04 Ultrasonik Ranger Finder, http.//acrome.com/robotic /part/R93-SRF04p.pdf (16 februari 2014: 10.33 WIB). 
[9] Datashee Flame detektor UVtron and Hamatsu Uvtron Drever Circuit c3704 series, http.//acrome.com/robotic/part/ Uvtron Flame.pdf (16 februari 2014:10.33 WIB).

\section{Biodata Penulis}

Darwison, dilahirkan di Payakumbuh, Sumatera Barat Indonesia. Pendidikan SD sampai SMA dilalui di kota Padang Sumatera Barat. Lulus SMA melanjutkan S1 Teknik Elektro bidang studi Elektronika ke ITS Surabaya. Selama mengikuti perkuliahan di ITS banyak pengalaman praktik yang didapat melalui sebagai asisten Praktikum, lomba dan Tugas Akhir. Pernah mendapat pengalaman elektronika di beberapa perusahaan yang memproduksi antara lain semen, plastik, obat nyamuk bakar dan lain-lain. Tahun 1995 diterima sebagai dosen S1 Teknik Elektro di Universitas Andalas Padang sampai sekarang. Tahun 2002 menyelesaikan S2 Teknik Elektro bidang studi Sistem Isyarat Elektronik di UGM Yogyakarta. Aktif di laboratorium untuk penelitian di bidang kontrol, mekatronika dan biomedika, pembimbing penelitian PKMT mahasiswa. Tahun 2002 sebagai kepala labor Elektronika Industri sampai 2012. Mata kuliah yang diajarkan di Jurusan Teknik Elektro dan Fakultas lain di Unand adalah Elektronika, Sistem kontrol, Interface, Operasional Amplifier, Sistem Digital, Sistem Cerdas dan Mikroprosesor \& Mikrokontroller. Penelitian yang dilakukan masih berkaitan dengan mikrokontroller, antara lain kontrol PLTB (Bayu), akses Moving Sign via HP, robot, petir, plasma, isolator tegangan tinggi dan gempa serta penelitian-penelitian lainnya memakai sistem cerdas. Pengabdian sesuai bidang penelitian seperti di Pauh, PKBM Karang Putih, Pesantren Alahan Panjang, dan KKN, mengadakan pelatihan interface \& Mikrokontroller untuk SMA, mahasiswa/umum, dan pembinaan \& pelatihan perancangan \& pembuatan moving sign. 